\title{
Tying and entry deterrence in vertically differentiated markets*
}

\author{
EUGEN KOvÁČ ${ }^{\dagger}$ \\ $\left(\mathrm{CERGE-EI^{ \ddagger } )}\right.$
}

March 2005

\begin{abstract}
This paper analyzes tying and bundling as an entry deterrence tool. It shows that a multi-product firm can defend its monopoly position in one market via tying also when it does not have market power in another market. This is shown on a model with two complementary goods, each of which is vertically differentiated and consumers' preferences for the goods are positively correlated. Some implications for competition policy are discussed.
\end{abstract}

Keywords: vertical differentiation, entry deterrence, tying, bundling JEL classification: L11, L12, L13, L41

I would like to qualify the paper for the Young Economist Award.

${ }^{*}$ The author would like to thank Avner Shaked and Dirk Engelmann for consultations and valuable suggestions, Kresimir Zigic and Ekaterina Goldfain for helpful comments. All errors are mine.

†Address: CERGE-EI, P.O.BOX 882, Politických vězňů 7, 11121 Prague 1, Czech Republic; URL: home.cerge-ei.cz/kovac; e-mail: eugen.kovac@cerge-ei.cz.

${ }^{\ddagger} \mathrm{A}$ joint workplace of the Center for Economic Research and Graduate Education, Charles University, and the Economics Institute of the Academy of Sciences of the Czech Republic. 


\section{Introduction}

Tying refers to the situation where a firm makes the purchase of one of its products conditional on the purchase of another of its products. The leverage theory claims that tying "provides a mechanism whereby a firm with monopoly power in one market can use the leverage provided by this power to foreclose sales in, and thereby monopolize, a second market" (Whinston 1990). Therefore, tying is one of the basic concepts in anti-trust laws and policies dealing with monopolization. ${ }^{1}$ Following the argument by Posner $(1976),{ }^{2}$ such cases require a proof of the monopoly power in the first market.

In Kováč (2004), I show that in the contrast to Posner's argument, tying may indeed be profitable for a multi-product firm which faces an equal competitor (a specialized single-product firm) on each market. ${ }^{3}$ In this paper I make a step further and provide a theoretical example in which a multiproduct firm without monopoly power in the first market uses tying to deter entry in the second market. I do not require that the competitors are symmetric, but that their products are differentiated vertically and moreover, I assume that the multi-product firm has a weaker position (it produces a low-quality product) in the first market.

The theoretical literature on entry deterrence and foreclosure by tying goes in line with the argument by Posner (1976). In his seminal paper, Whinston (1990) introduces a theoretical model to support the leverage hypothesis. He considers a multi-product firm which has monopoly power in one market and competes in price with a rival on another market. The author examines the implications of tying and concludes that it may lead to the foreclosure of the rival in the tied good market. However, the monopolist will engage in tying only if it can commit itself to doing so, which will consequently drive its rival out of the market. Whinston (1990) claims that tying is profitable for the monopolist precisely because of the "exclusionary effect on the market structure." The main difference of this paper from Whinston (1990) is that I do not require the multi-product firm to have a monopoly on the first market. Moreover, I consider the case where it has a weaker position than its competitor.

Protection of monopolized markets is a concept closely related to foreclosure. Carlton and Waldman (2002) argue that a dominant firm can use

\footnotetext{
${ }^{1}$ Recall, for example, the famous case of U.S. vs. Microsoft.

2 "... how could a tie-in be imposed unless such power existed?" (Posner 1976, p. 172).

${ }^{3}$ This means that at each separate market the firms can be interchanged without any effect. In Kováč (2004), I consider two symmetric markets: one for a horizontally differentiated product, the other for a homogeneous product.
} 
bundling ${ }^{4}$ to remain dominant in an industry with a rapid technological change. The authors apply their analysis to the Microsoft case and claim that Microsoft's tying and deterrence of Netscape's entry into the market for internet browsers could have increased social welfare. On the other hand, Choi and Stefanadis (2001) analyze simultaneous entry in two markets. They assume that the entry decisions exhibit economies of scope and show that tying may deter entry in both markets.

Rey and Tirole (2003) provide an excellent survey of the literature on foreclosure and incorporate all surveyed models into one framework. However, they analyze foreclosure only in cases when a monopoly power in another market is present. The authors also discuss a critique of the leverage hypothesis by the Chicago School who argue that for complementary products there is only one monopoly rent to extract and hence a monopolist has no incentives to monopolize a second market. ${ }^{5}$ Rey and Tirole (2003) conclude that the goods must be relatively independent so that the monopolist finds monopolization of the second market profitable.

Anther survey of tying and bundling is provided by Nalebuff (2003a, 2003b) in a report for the Department of Trade an Industry. In the first part of the report, Nalebuff (2003a) surveys different motives for bundling and tying, analyzes their consequences, in particular, anti-competitive effects, and provides policy recommendations. In the second part of the report, Nalebuff (2003b) illustrates his conclusion on particular anti-trust cases. In the analysis, he implicitly assumes that monopolization and entry deterrence by tying are possible only when the multi-product firm has monopoly power.

The purpose of this paper is to provide an example which shows that foreclosure is possible also without monopoly power when the goods are complements. I consider a multi-product firm which competes against a rival in one market and has monopoly power in another market, where it faces a potential entrant.

I consider three firms and two markets: one firm operates in both of them, one firm operates in the first market, and one firm is a potential entrant into the second market. I assume that each of the goods is differentiated vertically, consumers' preferences for them are positively correlated, and the markers are narrow enough in the sense that each of them cannot accommodate more than two firms in equilibrium. ${ }^{6}$ I consider a situation where the multi-product

\footnotetext{
${ }^{4}$ Bundling is a more general concept than tying and refers to a situation where a package containing at least two different products is offered. The practice in which the firm offers only the bundle is called pure bundling. The practice in which the firm offers the bundle as well as some of the products separately is called mixed bundling. See also Table 2, p. 7 .

${ }^{5}$ See Director and Levi (1956) and Posner (1976).

${ }^{6}$ Such markets were studied by Shaked and Sutton (1982) who call them natural
} 
firm offers a low quality product in the first market (where it faces a highquality competitor) and has a high quality product in the second market (where it faces a low-quality potential entrant); see Table $1 .{ }^{7}$ I show that the multi-product firm can protect its monopoly position in the second market against low-quality entrants. This is achieved by mixed bundling when the multi-product firm offers the monopolistic (second) good and the bundle. In other words, the first good is tied to the second (monopolistic) good.

\begin{tabular}{lcc}
\hline Quality & First market $\left(X_{D}\right)$ & Second market $\left(X_{E}\right)$ \\
\hline high & incumbent firm $(D)$ & multi-product firm $(M)$ \\
low & multi-product firm $(M)$ & potential entrant $(E)$ \\
\hline
\end{tabular}

Table 1: Markets structure

The incentive for tying as an entry deterrence tool is rather different from what is known in the literature. In this paper, tying is used as a tool for price discrimination between consumers with a high appreciation for quality and consumers with a low appreciation for quality. Furthermore, the price discrimination incentive for tying is different from the what is common in the literature, where the multi-product firm wants to discriminate between consumers who have a high and a low willingness to pay for the tied product. Moreover, in the present model the multi-product firm cannot leverage market power from the first market (as, for example, in Whinston (1990)), since it does not posses any.

By tying the monopolistic (second) good to the first good (of a low quality) the multi-product firm makes its low-quality first good unavailable separately. ${ }^{8}$ Therefore, the entrant's good (the second good) can be purchased only in a combination with the high-quality first good produced by the specialist incumbent firm. If the total quality ${ }^{9}$ of this combination is low (lower than the quality of the bundle), it will be purchased only by consumers with a low appreciation of quality. Moreover, if the market is narrow enough, the multi-product firm can in addition sell its high quality product in the second market (which will be purchased together with the incumbent specialist firm's high quality first product as the highest quality combination) in order leave no place for the low quality entrant. This will foreclose its sales and make entry unprofitable.

\footnotetext{
oligopolies.

${ }^{7}$ Obviously, in the absence of any form of bundling, there are four combinations available.

${ }^{8}$ It will be available only in the bundle.

${ }^{9}$ Here it just means the sum of qualities of separate products.
} 
The remainder of the paper is organized as follows. In Section 2, I describe the setup of the model. In Sections 3, 4, and 5, I analyze the multi-product firm's strategies when selling separate products, using pure bundling, and using mixed bundling, respectively. In Section 6, I investigate when the entry deterrence strategy is profitable for the multi-product firm. In Section 7, I conclude and discuss the relevance of my results for anti-trust policies. Appendix A contains proofs of all lemmas and propositions.

\section{Description of the model}

There are two markets for two indivisible complementary goods $X_{D}$ and $X_{E}$, two incumbent firms $M$ and $D$, and one potential entrant firm $E$. Firm $M$ (for multi-product) operates on both markets and firm $D$ (for duopoly) operates on the market for $X_{D}$. Firm $E$ (for entrant) plans to enter the market for good $X_{E}$. I assume that production of each good is costless, but entry exhibits certain fixed costs. Goods (varieties) $X_{D}$ produced by firms $M$ and $D$ are differentiated vertically. Similarly, if entry occurs, goods $X_{E}$ produced by firms $M$ and $E$ will be differentiated vertically. The structures of the markets os shown in Table 1 . For $i \in\{D, E\}$ denote $s_{M i}$ the quality of the good $X_{i}$ produced by firm $M$, and $s_{i}$ the quality of the good produced by its rival $i$.

Consumers are indexed by their taste for quality (appreciation of quality) $\theta$ which is uniformly distributed over the interval $[\underline{\theta}, \bar{\theta}]$. I analyze the case where consumers' tastes for quality for both goods are positively correlated. ${ }^{10}$ In particular, I assume that each consumer has the same taste for quality for both goods. ${ }^{11}$ Moreover, consumers have a positive marginal utility only from the first unit of both goods, i.e., they buy at most one unit. Formally, I consider the following utility function:

$$
U_{\theta}= \begin{cases}\theta\left(s_{d}+s_{e}\right)-p, & \text { if he buys goods } X_{D}, X_{E} \text { with } \\ & \text { qualities } s_{d}, s_{e} \text { by spending } p \\ & \text { where } d \in\{D, M D\}, e \in\{E, M E\} \\ & \text { if he does not buy }\end{cases}
$$

The parameter $\theta$ can be interpreted as taste for quality for a "package" containing goods $X_{D}, X_{E}$ with qualities $s_{d}, s_{e}$.

\footnotetext{
${ }^{10}$ This assumption is reasonable for complementary goods.

${ }^{11}$ This assumption is technical, to simplify the analysis, and to make the model tractable. The logic will still when the taste for quality is not the same, but highly positively correlated.
} 
Remark 1. Instead characterizing the consumers according to their taste for quality they can be characterized by their income, as in Shaked and Sutton (1982). This is a more realistic approach, as income is economically measurable and clearly defined variable. However, Tirole (1992, pp. 96-97) shows that both approaches are equivalent. When consumers differ by income, the parameter $1 / \theta$ can be interpreted as marginal rate of substitution between income and quality. Wealthier consumers correspond to higher values of $\theta$, because they have lower marginal utility of income. The assumption that the taste for quality is the same for both good means that the marginal rate substitution between income and quality is the same for both goods.

I will assume that all qualities are given exogenously and that the following inequalities hold:

$$
0<s_{M D}<s_{D}, \quad 0<s_{E}<s_{M E}, \quad s_{D}+s_{E}<s_{M D}+s_{M E} .
$$

The inequalities mean that firm $M$ produces a low quality version (variety) of good $D$. Furthermore, the entrant $E$ enters the market for good $X_{E}$ with a very low quality product, i.e., such that its quality is lower than $M$ 's quality and the quality of the combination of goods $X_{D}$ and $X_{E}$ is lower when purchased from $D$ and $E$ than when purchased only from $M .{ }^{12}$ The above assumptions yield the following ranking of qualities for potentially available combinations of goods $X_{D}$ and $X_{E}$ :

$$
s_{M D}+s_{E}<s_{D}+s_{E}<s_{M D}+s_{M E}<s_{D}+s_{M E} .
$$

In addition, I assume that

$$
\begin{aligned}
2 \underline{\theta} & <\bar{\theta} \\
\bar{\theta}\left(s_{D}-s_{M D}\right) & \leq \underline{\theta}\left(2 s_{D}+s_{M D}\right), \\
\bar{\theta}\left(s_{M E}-s_{E}\right) & \leq \underline{\theta}\left(2 s_{M E}+s_{E}\right) .
\end{aligned}
$$

The first assumption means that the market should be large enough to accommodate two firms. The other assumptions ensure that the markets are covered in equilibrium, when the goods are sold separately; see Tirole (1992, p. 296) for more details. I will call values of parameters admissible if they satisfy conditions (2)-(6). To simplify the analysis I denote

$$
\tau=\underline{\theta} / \bar{\theta}, \quad \Delta_{i}=s_{M i}-s_{i}(i \in\{D, E\}), \quad \rho=\Delta_{D} / \Delta_{E} .
$$

\footnotetext{
${ }^{12}$ I have explored also the remaining cases but this is the only one which leads to entry deterrence. Hence the other cases are not analyzed in this paper.
} 
Then the above assumptions can be rewritten as following:

$$
\begin{gathered}
\Delta_{D}<0, \quad \Delta_{E}>0, \quad \Delta_{D}+\Delta_{E}>0 \\
\max \left\{\frac{s_{D}-s_{M D}}{2 s_{D}+s_{M D}}, \frac{s_{M E}-s_{E}}{2 s_{M E}+s_{E}}\right\} \leq \tau \leq \frac{1}{2}
\end{gathered}
$$

It can be easily shown that $\left(s_{D}-s_{M D}\right) /\left(2 s_{D}+s_{M D}\right)<\left(s_{M E}-s_{E}\right) /\left(2 s_{M E}+s_{E}\right)$ if and only if $s_{D} s_{E}<s_{M D} s_{M E}$. Note also that (8) implies $\rho \in(-1,0)$.

The whole situation can be modelled as a three-stage game. In the first stage, firm $M$ decides which combination of goods $X_{D}$ and $X_{E}$ it will sell. Its options are listed in Table 2 . In the second stage, firm $E$ decides whether to enter the market for good $X_{E}$ by incurring a fixed cost $C .{ }^{13}$ In the third stage all firms compete in prices.

Remark 2. I assume that firm $M$ can precommit itself not to change its bundling strategy in a later stage (e.g., not to sell one of the goods separately if it previously decided otherwise). This precommitment can be achieved, for example, by a technological setting which may involve sunk costs; see Whinston (1990) and Nalebuff (2003a) for a more extensive discussion. In such cases it is reasonable to assume that the bundling strategy is chosen before the pricing decisions. If precommitment is not possible, the introduced timing is irrelevant. In this paper I show that the announcement of tying in the first stage can make firm E's second-stage entry unprofitable.

I analyze the pure-strategy equilibria of each subgame and look for a subgame perfect equilibrium of the whole game. To simplify the analysis, I consider equilibria where combinations of goods with a higher quality have also a higher price (otherwise nobody purchases the lower quality combination).

\begin{tabular}{ll}
\hline Strategy & Products offered by $M$ \\
\hline no bundling & $X_{D}$ and $X_{E}$ \\
pure bundling & bundle $\mathcal{M}=\left\{X_{D}, X_{E}\right\}$ \\
mixed bundling & $\left\{\begin{array}{l}\mathcal{M} \text { and } X_{D} \\
\mathcal{M} \text { and } X_{E} \\
\mathcal{M}, X_{D} \text { and } X_{E}\end{array}\right.$ \\
\hline
\end{tabular}

Table 2: Strategies of firm $M$ in the first stage

\footnotetext{
${ }^{13}$ The value of $C$ may depend on the entrant's quality. However, I assume that the qualities are given exogenously.
} 


\section{$3 \quad$ No bundling}

Consider first the benchmark case where firm $M$ decides to sell its products separately and firm $E$ enters the market. Let $p_{M D}, p_{M E}, p_{D}$, and $p_{E}$ be the prices of the respective goods offered by the firms. This notation will also be used in the following sections. In the absence of bundling, each consumer has four choices available (two for each good).

Obviously, if all customers are served with both goods, the two markets are independent. On the market for good $X_{E}$, a consumer with taste for quality $\theta$ buys product $X_{M E}$ if and only if $\theta>\theta^{*}$, where $\theta^{*}=\left(p_{M E}-p_{E}\right) / \Delta_{E}$ represents the indifferent consumer. ${ }^{14}$ Hence the firms' profits are $\Pi_{M E}=$ $p_{M E}\left(\theta^{*}-\underline{\theta}\right)$ and $\Pi_{E}=p_{E}\left(\bar{\theta}-\theta^{*}\right)$. Their maximization yields the following equilibrium prices and profits

$$
\begin{array}{ll}
p_{M E}=\frac{1}{3} \Delta_{E}(2 \bar{\theta}-\underline{\theta}), & p_{E}=\frac{1}{3} \Delta_{E}(\bar{\theta}-2 \underline{\theta}), \\
\Pi_{M E}=\frac{1}{9} \Delta_{E}(2 \bar{\theta}-\underline{\theta})^{2}, & \Pi_{E}=\frac{1}{9} \Delta_{E}(\bar{\theta}-2 \underline{\theta})^{2},
\end{array}
$$

and indifferent consumer $\theta^{*}=\frac{1}{3}(\underline{\theta}+\bar{\theta})$. Obviously, $p_{M E}>p_{E}$ and $\Pi_{M E}>\Pi_{E}$. Furthermore, condition (4) assures that $\underline{\theta}<\theta^{*}$ and (6) assures that the $\underline{\theta}$ consumer has a non-negative utility. Hence the market is in equilibrium covered by two firms.

The situation on the market for good $X_{D}$ is reverse in the sense that now firm $M$ has a low quality good. Hence the equilibrium prices and profits are (note that $\Delta_{D}<0$ )

$$
\begin{array}{ll}
p_{M D}=-\frac{1}{3} \Delta_{D}(\bar{\theta}-2 \underline{\theta}), & p_{D}=-\frac{1}{3} \Delta_{D}(2 \bar{\theta}-\underline{\theta}), \\
\Pi_{M D}=-\frac{1}{9} \Delta_{D}(\bar{\theta}-2 \underline{\theta})^{2}, & \Pi_{D}=-\frac{1}{9} \Delta_{D}(2 \bar{\theta}-\underline{\theta})^{2} .
\end{array}
$$

This yields firm's $M$ profit

$$
\begin{gathered}
\Pi_{M}^{\mathrm{noB}}=\Pi_{M D}+\Pi_{M E}= \\
=\frac{1}{9}\left(\left(-4 \Delta_{D}+\Delta_{E}\right) \underline{\theta}^{2}+4\left(\Delta_{D}-\Delta_{E}\right) \underline{\theta} \bar{\theta}+\left(-\Delta_{D}+4 \Delta_{E}\right) \bar{\theta}^{2}\right) .
\end{gathered}
$$

Each firm's profit is homogeneous of degree 1 in $\left(\Delta_{D}, \Delta_{E}\right)$ and homogeneous of degree 2 in $(\underline{\theta}, \bar{\theta})$. Hence, in certain cases, I will use a more convenient form of firm $M$ 's profit

$$
\Pi_{M}^{\mathrm{noB}}=\frac{1}{9}\left((4-\rho)+4(1-\rho) \tau+(4 \rho-1) \tau^{2}\right) \cdot \Delta_{E} \bar{\theta}^{2}
$$

\footnotetext{
${ }^{14} \mathrm{I}$ ignore the case of equality since it corresponds to a set containing a single consumer with zero measure.
} 
Firm $E$ enters the market whenever $\Pi_{E} \geq C$. If I denote $c=C /\left(\Delta_{E} \bar{\theta}^{2}\right)$ the "normalized" above condition is equivalent to $(1-2 \tau)^{2} \geq 9 c$, or $\tau \leq$ $\frac{1}{2}(1-3 \sqrt{c})$. Obviously, when $c=0$ firm $E$ enters for all values of $\tau$ satisfying (9). As $c$ increases, the range of values of $\tau$ where firm $E$ enters becomes smaller.

\section{Pure bundling}

In the case of pure bundling, the consumer has only two options: he can buy either the products from firms $D$ and $E$ separately (with qualities $s_{D}$ and $s_{E}$ ), or he can buy them in the bundle $\mathcal{M}$ from firm $M$. I assume that "unbundling" of goods in the bundle is impossible (or excessively costly) so that consumers cannot buy the bundle, abandon one product and buy it from another firm. This is related also to the notion of compatibility. From the market perspective, pure bundling is equivalent to making the products incompatible with rival ones; see, for example, Matutes and Regibeau (1992). ${ }^{15}$

Let $p_{M}$ denote the price of the bundle $\mathcal{M}$ offered by firm $M$. The current situation can be described as one vertically differentiated market with two products: the bundle $\mathcal{M}$ offered by firm $M$ (with quality $s_{M D}+s_{M E}$ and price $p_{M}$ ) and the combination ${ }^{16}$ of products $X_{D}$ and $X_{E}$ (with quality $s_{D}+s_{E}$ and price $\left.p_{D}+p_{E}\right)$. According to assumption (2), the former has a higher quality.

Obviously, a consumer with taste for quality $\theta$ buys the bundle $\mathcal{M}$ if and only if $\theta>\theta^{*}$, where $\theta^{*}=\left(p_{M}-p_{D}-p_{E}\right) /\left(\Delta_{D}+\Delta_{E}\right)$ represents the marginal (indifferent) consumer. Maximization of profits yields the following equilibrium prices

$$
p_{D}=p_{E}=\frac{1}{4}\left(\Delta_{D}+\Delta_{E}\right)(\bar{\theta}-2 \underline{\theta}), \quad p_{M}=\frac{1}{4}\left(\Delta_{D}+\Delta_{E}\right)(3 \bar{\theta}-2 \underline{\theta}),
$$

and equilibrium profits

$$
\begin{gathered}
\Pi_{D}=\Pi_{E}=\frac{1}{16}\left(\Delta_{D}+\Delta_{E}\right)(\bar{\theta}-2 \underline{\theta})^{2}=\frac{1}{16}(1+\rho)(1-2 \tau)^{2} \cdot \Delta_{E} \bar{\theta}^{2}, \\
\Pi_{M}^{\text {pureB }}=\frac{1}{16}\left(\Delta_{D}+\Delta_{E}\right)(3 \bar{\theta}-2 \underline{\theta})^{2}=\frac{1}{16}(1+\rho)(3-2 \tau)^{2} \cdot \Delta_{E} \bar{\theta}^{2} .
\end{gathered}
$$

Moreover, $\theta^{*}=\frac{1}{4}(2 \underline{\theta}+\bar{\theta})$. Similarly as for separate markets it is necessary to check whether the conditions for market coverage are satisfied in equilibrium.

\footnotetext{
${ }^{15}$ Printers and cartridges can serve as an example.

${ }^{16}$ In traditional economic literature a bundle means in general a combination of goods. To avoid misunderstandings I will refer to the "bundle" only as to the result of bundling, i.e., a package of goods $X_{M D}$ and $X_{M E}$ sold together by firm $M$.
} 
It is easy to verify that (4) implies $\underline{\theta}<\theta^{*}$ and (5) and (6) imply that the $\underline{\theta}$ consumer has a non-negative utility. Therefore, the market will be covered in equilibrium.

Firm $E$ enters the market if and only if $\frac{1}{16}(1+\rho)(1-2 \tau)^{2} \geq c$. As $\Pi_{E}$ is lower than in the no bundling subgame, entry is less likely to occur. However, for $c=0$, it occurs for all admissible values of parameters.

\section{$5 \quad$ Mixed bundling}

\subsection{Firm $M$ offers the bundle and good $X_{E}$ - the case of entry}

By offering good $X_{E}$ and the bundle firm $M$ makes the combination with the lowest quality $\left(s_{M D}+s_{E}\right)$ unavailable (assuming that firm $E$ enters). Hence, consumers are left with three options with the following ranking of qualities

$$
s_{D}+s_{E}<s_{M D}+s_{M E}<s_{D}+s_{M E} .
$$

The marginal consumer who is indifferent between buying the goods from firms $D$ and $E$, and buying the bundle is characterized by $\theta_{2}^{*}=\left(p_{M}-\right.$ $\left.p_{D}-p_{E}\right) /\left(\Delta_{D}+\Delta_{E}\right)$. The marginal consumer who is indifferent between buying the bundle and highest quality combination is characterized by $\theta_{3}^{*}=$ $\left(p_{M}-p_{D}-p_{M E}\right) / \Delta_{D}$, where $\underline{\theta}<\theta_{2}^{*}<\theta_{3}^{*}<\bar{\theta}$. These yield the following profits

$$
\begin{aligned}
\Pi_{M} & =p_{M}\left(\theta_{3}^{*}-\theta_{2}^{*}\right)+p_{M E}\left(\bar{\theta}-\theta_{3}^{*}\right), \\
\Pi_{D} & =p_{D}\left(\theta_{2}^{*}-\underline{\theta}+\bar{\theta}-\theta_{3}^{*}\right), \\
\Pi_{E} & =p_{E}\left(\theta_{2}^{*}-\underline{\theta}\right) .
\end{aligned}
$$

The following proposition shows that under certain condition, there may be no place for firm $E$ on the market.

Proposition 1. Assume that

$$
\tau \geq \frac{3+2 \rho}{2(3+\rho)}
$$

and firm $M$ decides to sell good $X_{E}$ as well as the bundle. If firm $E$ enters the market, it cannot obtain a positive market share whenever firms $D$ and $M$ maximize their profits.

Proof. See Appendix A. 
Remark 3. Note also that the converse holds. This means that whenever (15) is not true, firm $E$ can have a positive market share for $p_{E}$ small enough. This is directly observable from the expression for $\theta_{2}^{*}$.

The above proposition implies that under (15), entry is not profitable regardless of the entry costs $C$. Condition (15) means that the market should be narrow enough to leave no place for the entrant. It is easy to recognize that the right-hand side from (15) is increasing in $\rho$ on the interval $(-1,0)$, with infimum $\frac{1}{4}$ (as $\rho \rightarrow-1^{+}$) and supremum $\frac{1}{2}$ (as $\rho \rightarrow 0^{-}$). Hence for any $\rho \in(-1,0)$ there exists $\tau \leq \frac{1}{2}$ such that (15) holds.

To analyze the effect of firm $E$ 's quality, assume that firm $E$ enters with a lower quality. Then the value of $\Delta_{E}$ will be higher and hence $\rho$ will be higher (closer to 0). Therefore, (15) is more restrictive. This means that the lower is the quality firm $E$ enters with, the more likely is entry deterrence.

\subsection{Firm $M$ offers the bundle and good $X_{E}$ - the case of no entry}

In this subsection I analyze the case when firm $E$ decides not to enter. As mentioned in Remark 2, firm $M$ commits to its bundling strategy in the first stage. Henceforth, although firm $E$ does not enter, firm $M$ has to sell the bundle and good $X_{E} \cdot{ }^{17}$ In this case the consumer has only two options: he can buy either the bundle, or good $X_{D}$ from firm $D$ together with good $X_{E}$ from firm $M$. Denote $\theta_{3}^{*}=\left(p_{M}-p_{D}-p_{M E}\right) / \Delta_{D}$ the consumer who is indifferent between them. Further denote $\theta_{0}^{*}=\left(p_{D}+p_{M E}\right) /\left(s_{D}+s_{M E}\right)$ the consumer who is indifferent between buying the latter combination and not buying at all. The following lemmas specify certain situations which do not occur in equilibrium.

Lemma 1. Assume that firm $M$ offers the bundle and good $X_{E}$ and firm $E$ does not enter the market. If firm $M$ maximizes its profit, then it is not possible that both combinations have a positive market share ${ }^{18}$ and the market is overcovered.

Lemma 2. Assume that firm $M$ offers the bundle and good $X_{E}$ and firm $E$ does not enter the market. If firm $M$ maximizes its profit, then it is not possible that both combinations have a positive market share and the market is exactly covered.

\footnotetext{
${ }^{17}$ Firm $M$ is not allowed to change its strategy ex-post. However, it may charge a high price for some of its products so that nobody will buy it.

${ }^{18}$ I.e., they are purchased by a positive measures of consumers.
} 
The following proposition specifies the equilibrium in this subgame.

Proposition 2. Assume that firm $M$ offers the bundle and good $X_{E}$ and firm $E$ does not enter the market. Then the equilibrium prices are

$$
\begin{aligned}
p_{D} & =-\frac{1}{3} \Delta_{D} \bar{\theta} \\
p_{M} & =\frac{1}{2}\left(s_{M D}+s_{M E}\right) \bar{\theta} \\
p_{M E} & =\frac{1}{2}\left(s_{M D}+s_{M E}\right) \bar{\theta}+\frac{1}{3} \Delta_{D} \bar{\theta}
\end{aligned}
$$

yielding an undercovered market and profits

$$
\begin{aligned}
\Pi_{D} & =-\frac{1}{9} \Delta_{D} \bar{\theta}^{2} \\
\Pi_{M}^{\text {deter }} & =-\frac{1}{9} \Delta_{D} \bar{\theta}^{2}+\frac{1}{4}\left(s_{M D}+s_{M E}\right) \bar{\theta}^{2} .
\end{aligned}
$$

Note that the price of the bundle is lower than the price of good $X_{E}$ when sold separately. This is a consequence of the assumption that unbundling is impossible. This form of pricing occurs in reality. Nalebuff (2003a, p. 31-32) provides an example of cars and radios, where cars with radios are cheaper than cars without radios. On one hand it may appear counterintuitive. On the other hand it means that consumers with high appreciation of quality are charged a higher price.

\subsection{Firm $M$ offers the bundle and good $X_{D}$}

By offering good $X_{D}$ and the bundle firm $M$ makes the combination with the highest quality $\left(s_{D}+s_{M E}\right)$ unavailable. Consumers are left with three options with the following ranking of qualities

$$
s_{M D}+s_{E}<s_{D}+s_{E}<s_{M D}+s_{M E} .
$$

The marginal consumers are characterized by $\theta_{1}^{*}=\left(p_{M D}-p_{D}\right) / \Delta_{D}$ and $\theta_{2}^{*}=\left(p_{M}-p_{D}-p_{E}\right) /\left(\Delta_{D}+\Delta_{E}\right)$.

Proposition 3. Assume that

$$
\tau \geq \frac{1+\rho}{5+\rho}
$$

firm $E$ enters the market, and firm $M$ offers the bundle and good $X_{D}$. Then there is no equilibrium of this subgame, such that the lowest quality combination is purchased by a positive measure of consumers. 
The above proposition implies that under condition (17), although firm $M$ decides to offer (in addition to the bundle) product $X_{D}$, it prefers that nobody buys it. Hence any equilibrium in this subgame will be outcome equivalent ${ }^{19}$ to an equilibrium of the pure bundling subgame. The equilibrium prices and profits are then given by (13) and (14), where $p_{M D}$ is high enough so that nobody buys firm $M$ 's good $X_{D}$ together firm $E$ 's good $X_{E}$.

\subsection{Firm $M$ offers the bundle and goods $X_{D}, X_{E}$}

In this case, the consumer has all combinations of goods $X_{D}$ and $X_{E}$ available, with ranking of qualities given by (3). Moreover, he can buy the products from firm $M$ either in the bundle (for the price $p_{M}$ ) or separately (for the price $\left.p_{M D}+p_{M E}\right)$. Obviously offering a bundle makes sense only if $p_{M}<$ $p_{M D}+p_{M E}$. Otherwise nobody buys it and the situation is equivalent to selling separate products.

The marginal consumers are characterized by $\theta_{1}^{*}=\left(p_{M D}-p_{D}\right) / \Delta_{D}, \theta_{2}^{*}=$ $\left(p_{M}-p_{D}-p_{E}\right) /\left(\Delta_{D}+\Delta_{E}\right)$, and $\theta_{3}^{*}=\left(p_{M}-p_{D}-p_{M E}\right) / \Delta_{D}$, where $\underline{\theta}<\theta_{1}^{*}<$ $\theta_{2}^{*}<\theta_{3}^{*}<\bar{\theta}$.

Proposition 4. Assume that

$$
\tau \geq \frac{2(1+\rho)}{7+4 \rho}
$$

firm $E$ enters the market, and firm $M$ offers the bundle and both goods $X_{D}$ and $X_{E}$. Then nobody buys the lowest quality combination whenever firms $M$ and $D$ maximize their profits.

The above proposition implies that under condition (18), although firm $M$ decides to offer product $X_{D}$ too, it prefers when nobody buys it. Hence any equilibrium in this subgame will be outcome equivalent to an equilibrium of the subgame where firm $M$ offers the bundle and good $X_{E}$, causing no entry by firm $E$. The appropriate equilibrium prices are specified in Proposition 2.

\section{$6 \quad$ Entry deterrence}

In this section I compare entry deterrence equilibrium with other equilibrium outcomes. In order to find out when entry deterrence occurs in subgame perfect equilibrium, it can be easily established that condition (15) implies

\footnotetext{
${ }^{19}$ Two equilibria are outcome equivalent when they yield the same profits to each firm and the same utility to each consumer.
} 
conditions (17) and (18); see also Figure 1 in Appendix C. This means that under condition (15), any equilibrium of the third stage after the entry occurs is outcome equivalent either to the equilibrium of the pure bundling subgame, or to the equilibrium of the no bundling subgame. Hence, entry deterrence is a subgame perfect equilibrium if and only if it is more profitable for firm $M$ than the pure bundling and no bundling equilibria.

To specify the subgame perfect equilibrium it remains to compare firm $M$ 's equilibrium profits $\Pi_{M}^{\mathrm{noB}}, \Pi_{M}^{\mathrm{pureB}}$, and $\Pi_{M}^{\text {deter }}$, given by (12), (14), and (16), respectively, under assumption (15).

Lemma 3. For all admissible values of parameters such that condition (15) holds, the equilibrium profit in the pure bundling subgame is higher than in the no bundling subgame.

Remark 4. This result conforms to the results in Kováč (2004) in the sense that also a multi-product firm without monopoly power can find tying profitable.

Now, it remains to compare profit $\Pi_{M}^{\text {pure }}$ in the pure bundling subgame to the entry deterrence profit $\Pi_{M}^{\text {deter }}$. The following proposition and its corollary show that the profit $\Pi_{M}^{\text {deter }}$ is higher than $\Pi_{M}^{\text {pureB }}$ for a large set of admissible values of parameters.

Proposition 5. For any values $s_{D}, s_{E}, s_{M D}$, and $s_{M E}$ satisfying conditions (2) and for any $\tau \leq \frac{1}{2}$, the inequality $\Pi_{M}^{\text {deter }}>\Pi_{M}^{\text {pureB }}$ is equivalent to $\tau>\tau^{*}$, where

$$
\tau^{*}=\frac{3}{2}-\frac{1}{3} \sqrt{\frac{5 s_{M D}+9 s_{M E}+4 s_{D}}{s_{M D}+s_{M E}-s_{D}-s_{E}}}
$$

and $\tau^{*}<\frac{1}{2}$.

Corollary 1. For any values $s_{D}, s_{E}, s_{M D}$, and $s_{M E}$ satisfying conditions (2), there exists an open set of admissible values of $\tau$ such that entry deterrence is a subgame perfect strategy.

As the result of the previous proposition depends on five parameters, it cannot be visualized easily. For a better illustration I will analyze the extreme case where the inequality $\Pi_{M}^{\text {deter }}>\Pi_{M}^{\text {pureB }}$ holds for all admissible values of $\tau$ that satisfy (15). This occurs when at least one of the following three conditions is satisfied:

$$
\tau^{*}<\frac{s_{D}-s_{M D}}{2 s_{D}+s_{M D}}, \quad \text { or } \quad \tau^{*}<\frac{s_{M E}-s_{E}}{2 s_{M E}+s_{E}}, \quad \text { or } \quad \tau^{*}<\frac{3+2 \rho}{2(3+\rho)} .
$$

I conjecture that for all admissible values of parameters, at least one of the above conditions is satisfied. 
Conjecture 1. Assume that the values of parameters are admissible and satisfy condition (15). Then in the subgame-perfect equilibrium, firm $M$ uses tying to deter entry of firm E.

Partial proof, results of numerical simulations and visualization of Conjecture 1 are presented in Appendix B and C.

\section{Conclusion}

In this paper I analyze a situation where a multi-product firm competes against a specialist firm in one market and faces a potential entrant in the second market. In the present model, I consider two markets for complementary products, produced by the multi-product firm. Each of them is produced by another single-product (specialist) firm, one of them is incumbent and the other is a potential entrant. In the same market, the products produced by different firms are differentiated vertically, where the multi-product firm has a lower quality than the incumbent (in the fist market), but a higher quality than the potential entrant (in the second market). In the paper, I show that the multi-product firm can use tying to deter entry in the second market even when it does not have monopoly power in the first market. This result is relevant for anti-trust policies since it illustrates an anti-competitive practice which was until now not taken into account (as to my best knowledge).

The understanding of this issue could be in the future extended in several directions.

- First, in the paper I consider the qualities of the goods given exogenously. It would be interesting to analyze an extension of the presented model, where quality is determined endogenously, at least by the entrant firm.

- Second, the markets considered in this paper are narrow in the sense that each of them cannot accommodate more than two firms in equilibrium. A relevant question is how the results will change for wider markets.

This analysis would improve understanding of motives for tying and would help us to choose appropriate remedies when designing competition policy. 


\section{References}

Carlton, Dennis W. and Michael Waldman, "The Strategic Use of Tying to Preserve and Create Market Power in Evolving Industries," The RAND Journal of Economics, 2002, 33 (2), 194-220.

Choi, Jay Pil and Christodoulos Stefanadis, "Tying, Investment, and the Dynamic Leverage Theory," The RAND Journal of Economics, 2001, 32 (1), 52-71.

Director, Aaron and Edward Levi, "Law and Future: Trade Regulation," North-western University Law Review, 1956, 51, 281-296.

Kováč, Eugen, "Tying by a non-monopolist," CERGE-EI Working Paper No. 225, 2004.

Matutes, Carmen and Pierre Regibeau, "Compatibility and Bundling of Complementary Goods in a Duopoly," Journal of Industrial Economics, 1992, 40 (1), 37-54.

Nalebuff, Barry, "Bundling, Tying, and Portfolio Effects, Part 1 - Conceptual Issues," DTI Economics Paper No. 1, 2003.

_ , "Bundling, Tying, and Portfolio Effects, Part 2 - Case Studies," DTI Economics Paper No. 2, 2003.

Posner, Richard A., Antitrust Law: An Economic Perspective, Chicago: University of Chicago Press, 1976.

Rey, Patric and Jean Tirole, "A Primer on Foreclosure," in Mark Armstrong and Rob Porter, eds., Handbook of Industrial Organization, vol. III, (forthcoming), 2003.

Shaked, Avner and John Sutton, "Natural oligopolies," Econometrica, 1982, 51 (1), 1469-1483.

Tirole, Jean, The Theory of Industrial Organization, 5th ed., Cambridge, Massachusetts: The MIT Press, 1992.

Whinston, Michael D., "Tying, Foreclosure, and Exclusion," The American Economic Review, 1990, 80 (4), 837-859. 


\section{A Appendix: Proofs}

Proof of Proposition 1. Assuming (15), I will show that $\theta_{2}^{*}<\underline{\theta}$ for any positive $p_{E}$ whenever firms $M$ and $E$ maximize their profits. The first order conditions for maximization of firm $M$ 's and $D$ 's profits are $^{20}$

$$
\begin{aligned}
& 2 \Delta_{E} p_{M}-\Delta_{E} p_{D}-2\left(\Delta_{D}+\Delta_{E}\right) p_{M E}+\Delta_{D} p_{E}=0, \\
& 2 p_{M}-p_{D}-2 p_{M E}=\Delta_{D} \bar{\theta}, \\
& \Delta_{E} p_{M}-2 \Delta_{E} p_{D}-\left(\Delta_{D}+\Delta_{E}\right) p_{M E}+\Delta_{D} p_{E}=\Delta_{D}\left(\Delta_{D}+\Delta_{E}\right)(\bar{\theta}-\underline{\theta}) .
\end{aligned}
$$

Solution of this system (with $p_{E}$ as parameter) is the following

$$
\begin{aligned}
p_{M}= & \frac{1}{6 \Delta_{E}}\left(\left(\Delta_{D}+3 \Delta_{E}\right) p_{E}+2 \Delta_{D}\left(\Delta_{D}+\Delta_{E}\right) \underline{\theta}+\right. \\
& \left.+\left(-2 \Delta_{D}^{2}+\Delta_{D} \Delta_{E}+3 \Delta_{E}^{2}\right) \bar{\theta}\right), \\
p_{M E}= & \frac{1}{2}\left(p_{E}+\Delta_{E} \bar{\theta}\right), \\
p_{D}= & \frac{\Delta_{D}}{3 \Delta_{E}}\left(p_{E}-2\left(\Delta_{D}+\Delta_{E}\right)(\bar{\theta}-\underline{\theta})\right) .
\end{aligned}
$$

Hence

$$
\theta_{2}^{*}-\underline{\theta}=-\frac{\Delta_{D}+3 \Delta_{E}}{6 \Delta_{E}\left(\Delta_{D}+\Delta_{E}\right)} p_{E}+\frac{1}{6 \Delta_{E}}\left(-2\left(\Delta_{D}+3 \Delta_{E}\right) \underline{\theta}+\left(2 \Delta_{D}+3 \Delta_{E}\right) \bar{\theta}\right) .
$$

It is easy to observe that the coefficient at $p_{E}$ is negative. Moreover, the last term is non-positive if and only if (15) holds. In this case $\theta_{2}^{*}<\underline{\theta}$ for any positive $p_{E}$. Hence firm $E$ cannot achieve a positive market share.

Proof of Lemma 1. If both combinations are purchased by a positive measure of consumers and the market is overcovered, then $\theta_{0}^{*}<\underline{\theta}<\theta_{3}^{*}<\bar{\theta}$. In this case

$$
\Pi_{M}=p_{M E}\left(\bar{\theta}-\theta_{3}^{*}\right)+p_{M}\left(\theta_{3}^{*}-\underline{\theta}\right) .
$$

A direct computation yields

which implies

$$
\begin{aligned}
\frac{\partial \Pi_{M}}{\partial p_{M}} & =\frac{2 p_{M}-p_{D}-2 p_{M E}}{\Delta_{D}}-\underline{\theta} \\
\frac{\partial \Pi_{M}}{\partial p_{M E}} & =-\frac{2 p_{M}-p_{D}-2 p_{M E}}{\Delta_{D}}+\bar{\theta}
\end{aligned}
$$

$$
\frac{\partial \Pi_{M}}{\partial p_{M}}+\frac{\partial \Pi_{M}}{\partial p_{M E}}=\bar{\theta}-\underline{\theta}>0 .
$$

Hence at least one of the derivatives is positive. This means that $\Pi_{M}$ has no interior maximum, i.e., such that $\theta_{0}<\underline{\theta}<\theta_{3}^{*}<\bar{\theta}$.

\footnotetext{
${ }^{20}$ Because the profits are quadratic in prices, it is easy to check that second-order conditions also hold for any prices.
} 
Proof of Lemma 2. If the market is exactly covered, then $\theta_{0}^{*}=\underline{\theta}<\theta_{3}^{*}<\bar{\theta}$. Hence, $p_{M}=\left(s_{M D}+s_{M E}\right) \underline{\theta}$. If $p_{M}<\left(s_{M D}+s_{M E}\right) \underline{\theta}$, the market is overcovered (i.e., $\theta_{0}^{*}<$ $\underline{\theta}$ ) and firm $M$ 's profit is given by (21). On the other hand, if $p_{M}>\left(s_{M D}+s_{M E}\right) \underline{\theta}$, the market is undercovered (i.e., $\theta_{0}^{*}>\underline{\theta}$ ) and firm $M$ 's profit is

$$
\Pi_{M}=p_{M E}\left(\bar{\theta}-\theta_{3}^{*}\right)+p_{M}\left(\theta_{3}^{*}-\theta_{0}^{*}\right) .
$$

When firm $M$ maximizes its profit, the following conditions hold: $\partial \Pi_{M} / \partial p_{M E}=0$ and $\partial \Pi_{M} /\left.\partial p_{M}\right|_{p_{M}=\left(s_{M D}+s_{M E}\right) \underline{\theta}} ^{+} \leq 0$. Substitution yields $\left(2 p_{M}-2 p_{M E}-p_{D}\right) / \Delta_{D}=$ $\bar{\theta}$ and $\left(2 p_{M}-2 p_{M E}-p_{D}\right) / \Delta_{D} \leq 2 p_{M} /\left(s_{M D}+s_{M E}\right)$. Hence $\bar{\theta} \leq 2 \underline{\theta}$, which contradicts (4).

Proof of Proposition 2. According to Lemmas 1 and 2, the market needs to be undercovered in equilibrium. In this case, firm $M$ 's profit is specified by $(22)$ and firm $D$ 's profit is $\Pi_{D}=p_{D}\left(\bar{\theta}-\theta_{3}^{*}\right)$. Their maximization yields the following the following first order conditions

$$
\begin{aligned}
2 p_{M}-2 p_{M E}-p_{D} & =2 p_{M} \Delta_{D} /\left(s_{M D}+s_{M E}\right) \\
2 p_{M}-2 p_{M E}-p_{D} & =\Delta_{D} \bar{\theta} \\
p_{M}-p_{M E}-2 p_{D} & =\Delta_{D} \bar{\theta}
\end{aligned}
$$

Obviously, the prices specified in the proposition form the unique solution of the above system. The profits are obtained after substitution. Note that $\theta_{0}^{*}=$ $p_{M} /\left(s_{M D}+s_{M E}\right)=\frac{1}{2} \bar{\theta}>\underline{\theta}$, hence the market is indeed undercovered.

Proof of Proposition 3. Each of the three combinations available is purchased by consumers with a positive measure if and only if $\underline{\theta}<\theta_{1}^{*}<\theta_{2}^{*}<\bar{\theta}$. I will show that the condition (17) implies $\theta_{1}^{*}<\underline{\theta}$.

Firms' profits can be written as follows: $\Pi_{M}=p_{M}\left(\bar{\theta}-\theta_{2}^{*}\right)+p_{M D}\left(\theta_{1}^{*}-\underline{\theta}\right)$, $\Pi_{D}=p_{D}\left(\theta_{2}^{*}-\theta_{1}^{*}\right)$, and $\Pi_{E}=p_{E}\left(\theta_{2}^{*}-\underline{\theta}\right)$. Maximization of these profits yields the following equilibrium prices:

$$
\begin{aligned}
p_{M} & =\frac{3 \Delta_{E}\left(\Delta_{D}+\Delta_{E}\right)}{\Delta_{D}+9 \Delta_{E}}(2 \bar{\theta}-\underline{\theta}), \\
p_{M D} & =-\frac{\Delta_{D}}{\Delta_{D}+9 \Delta_{E}}\left(\left(\Delta_{D}+\Delta_{E}\right) \bar{\theta}-\left(\Delta_{D}+5 \Delta_{E}\right) \underline{\theta}\right), \\
p_{D} & =-\frac{\Delta_{D}\left(\Delta_{D}+\Delta_{E}\right)}{\Delta_{D}+9 \Delta_{E}}(2 \bar{\theta}-\underline{\theta}), \\
p_{E} & =-\frac{\Delta_{D}}{\Delta_{D}+9 \Delta_{E}}\left(\left(\Delta_{D}+3 \Delta_{E}\right) \bar{\theta}-\left(\Delta_{D}+6 \Delta_{E}\right) \underline{\theta}\right) .
\end{aligned}
$$

Under these prices

$$
\theta_{1}^{*}=\frac{1}{\Delta_{D}+9 \Delta_{E}}\left(\left(\Delta_{D}+\Delta_{E}\right) \bar{\theta}+4 \Delta_{E} \underline{\theta}\right) .
$$

Obviously, the condition (17) is equivalent to $\theta_{1}^{*}<\underline{\theta}$. 
Proof of Proposition 4. Each of the four combinations available is purchased by consumers with a positive measure if and only if $\underline{\theta}<\theta_{1}^{*}<\theta_{2}^{*}<\theta_{3}^{*}<\bar{\theta}$. Similarly as in the Proof of Proposition 1, I will consider $p_{D}$ as parameter and show that the condition (18) implies $\theta_{1}^{*}<\underline{\theta}$ for any $p_{D}>0$.

Firms' profits can be written as follows: $\Pi_{M}=p_{M}\left(\theta_{3}^{*}-\theta_{2}^{*}\right)+p_{M D}\left(\theta_{1}^{*}-\underline{\theta}\right)+$ $p_{M E}\left(\bar{\theta}-\theta_{3}^{*}\right), \Pi_{D}=p_{D}\left(\theta_{2}^{*}-\theta_{1}^{*}+\bar{\theta}-\theta_{3}^{*}\right)$, and $\Pi_{E}=p_{E}\left(\theta_{2}^{*}-\underline{\theta}\right)$. Maximization of firm $M$ 's and firm $D$ 's profits yields:

$$
\begin{aligned}
p_{M} & =\frac{1}{6\left(\Delta_{D}+2 \Delta_{E}\right)}\left(2\left(2 \Delta_{D}+3 \Delta_{E}\right) p_{E}+\left(D_{1}+\Delta_{E}\right)\left(\Delta_{D} \underline{\theta}+\left(\Delta_{D}+6 \Delta_{E}\right) \bar{\theta}\right)\right), \\
p_{M D} & =\frac{\Delta_{D}}{6\left(\Delta_{D}+2 \Delta_{E}\right)}\left(p_{E}+\left(4 \Delta_{D}+7 \Delta_{E}\right) \underline{\theta}-2\left(\Delta_{D}+\Delta_{E}\right) \bar{\theta}\right), \\
p_{M E} & =\frac{1}{2}\left(p_{E}+\Delta_{E} \bar{\theta}\right) \\
p_{D} & =\frac{\Delta_{D}}{3\left(\Delta_{D}+2 \Delta_{E}\right)}\left(p_{E}-\left(\Delta_{D}+\Delta_{E}\right)(2 \bar{\theta}-\underline{\theta}) .\right.
\end{aligned}
$$

Under these prices

$$
\theta_{1}^{*}-\underline{\theta}=-\frac{1}{6\left(\Delta_{D}+2 \Delta_{E}\right)} p_{E}+\frac{1}{6\left(\Delta_{D}+2 \Delta_{E}\right)}\left(2\left(\Delta_{D}+\Delta_{E}\right) \bar{\theta}-\left(4 \Delta_{D}+7 \Delta_{E}\right) \underline{\theta}\right) .
$$

Obviously, $\theta_{1}^{*}<\underline{\theta}$ for any $p_{E}>0$, whenever the condition (18) holds. ${ }^{21}$

Proof of Lemma 3. It can be easily established that for $\rho \in(-1,0)$ and $\tau \in\left(0, \frac{1}{2}\right)$ the profit $\Pi_{M}^{\text {pureB }}$ from the pure bundling subgame is higher than the profit $\Pi_{M}^{\text {noB }}$ from the no bundling subgame if and only if

$$
\tau>\frac{1}{2(13-7 \rho)}\left(43+11 \rho-2 \sqrt{407-49 \rho+200 \rho^{2}}\right) .
$$

It can be easily shown that for any $\rho \in(-1,0)$ the following inequalities hold:

$$
\frac{1}{2(13-7 \rho)}\left(43+11 \rho-2 \sqrt{407-49 \rho+200 \rho^{2}}\right)<\frac{1}{4}<\frac{3+2 \rho}{2(3+\rho)} .
$$

This directly implies that $\Pi_{M}^{\mathrm{pureB}}>\Pi_{M}^{\mathrm{noB}}$. Figure 2 in Appendix $\mathrm{C}$ shows the graph of the right-hand side of the above expression together with the right-hand side of (15).

Proof of Proposition 5. Consider $s_{D}, s_{E}, s_{M D}$, and $s_{M E}$ fixed and denote

$$
f(\tau)=\bar{\theta}^{2}\left(\Pi_{M}^{\text {pureB }}-\Pi_{M}^{\text {deter }}\right) .
$$

Obviously $f$ is quadratic function of $\tau$ and condition (2) implies that

$$
f^{\prime}(\tau)=\frac{1}{4}\left(s_{D}+s_{E}-s_{M D}-s_{M E}\right)(3-2 \tau)<0,
$$

${ }^{21}$ Note that $\theta_{1}^{*}-\underline{\theta}=-p_{M D} / \Delta_{D}$. 
whenever $\tau<\frac{3}{2}$, and $f^{\prime \prime}(\tau)>0$. Hence $f$ is convex, attains maximum for $\tau=\frac{3}{2}$, and is decreasing for all $\tau \leq \frac{1}{2}$. It can be easily computed that the equation $f(\tau)=0$ has solutions

$$
\tau_{1,2}=\frac{3}{2} \pm \frac{1}{3} \sqrt{\frac{5 s_{M D}+9 s_{M E}+4 s_{D}}{s_{M D}+s_{M E}-s_{D}-s_{E}}} .
$$

Let $\tau_{1}>\tau_{2}$. Obviously $\tau_{1}>\frac{3}{2}$ and the inequality $\tau_{2}<\frac{1}{2}$ is equivalent to $-13 s_{D}-$ $9 s_{E}+4 s_{M D}<0$, which holds as $s_{M D}<s_{D}$.

Hence, I have shown that for $\tau \leq \frac{1}{2}$, the inequality $f(\tau)<0$ is equivalent to $\tau>\tau_{2}$. 


\section{B Appendix: Conjecture 1}

It can be easily established that none of the conditions (20) implies the other two. ${ }^{22}$ The first two right-hand-side expressions have infimum equal to zero on the set of all admissible values of parameters. A direct computation shows that for admissible values parameters, the inequality $\tau^{*}<0$ is equivalent to

$$
97 s_{D}+81 s_{E}>61 s_{M D}+45 s_{M E} .
$$

On the other hand, the third expression from (20) has infimum equal to $\frac{1}{4}$ when $\rho \in(-1,0)$; see also Figure 1 in Appendix C. A direct computation shows that for admissible values parameters, the inequality $\tau^{*}<\frac{1}{4}$ is equivalent to

$$
289 s_{D}+225 s_{E}>145 s_{M D}+81 s_{M E} .
$$

As all relevant conditions, i.e., (2)-(6), (15), and (19), are homogeneous of degree 1 in $\left(s_{D}, s_{E}, s_{M D}, s_{M E}\right)$, I can use a normalization $s_{M D}+s_{M E}=1$, which represents the total quality of the bundle. Note that under this normalization the set of all admissible values of parameters is bounded (from below by 0 , from above by 1$)$. Then the set of parameters $\left(s_{D}, s_{E}, s_{M D}\right)$ where the admissibility conditions (2) hold is the interior of a tetrahedron with vertices $(0,0,0),(0,1,0),(1,0,0)$, and $(1,0,1)$ in the $\left(s_{D}, s_{E}, s_{M D}\right)$-space. Moreover, after the normalization, condition (24) becomes $289 s_{D}+225 s_{E}>81+64 s_{M D}$, which holds whenever $s_{D}+s_{E}>\frac{9}{25}$, as $s_{M D}<s_{D}$. Figure 3 in Appendix $\mathrm{C}$ shows the tetrahedron representing the set of admissible values of parameters. Condition (24) is represented by the open half-space $Z_{1} Z_{2} Z_{3}$ which does not contain point $(0,0,0)$.

To verify the third condition from (20) for the rest of admissible values of parameters I used numerical simulations. ${ }^{23}$ From them I conjecture that it holds for all admissible values of parameters. ${ }^{24}$ This means entry deterrence is profitable for firm $M$ for all admissible values of parameters such that condition (15) holds.

\footnotetext{
${ }^{22}$ For example, for $s_{D}=0.2, s_{E}=0.2, s_{M D}=0.1, s_{M E}=0.8$ the right-hand sides are $0.35,0.2$, and 0.475 , respectively. Taking $s_{M D}=0.01$ instead, yields values 0.3624 , 0.4634 , and 0.4564 .

${ }^{23}$ I used a grid of $100 \times 100 \times 100$ on the set $[0,1] \times[0,1] \times[0,1]$.

${ }^{24}$ I also checked numerically the first two conditions from (20). Obviously, after normalization (23) reduces to $97 s_{D}+81 s_{E}>45+16 s_{M D}$, which holds whenever $s_{D}+s_{E}>\frac{5}{9}$. Using a grid of $1000 \times 100 \times 1000$ on the set $\left[0, \frac{5}{9}\right] \times\left[0, \frac{5}{9}\right] \times\left[0, \frac{5}{9}\right]$, the simulations indicate that the first or the second condition is satisfied whenever $s_{D}>0.04$, or $s_{E}>0.31$, or $s_{M D}>0.04$.
} 


\section{Appendix: Figures}

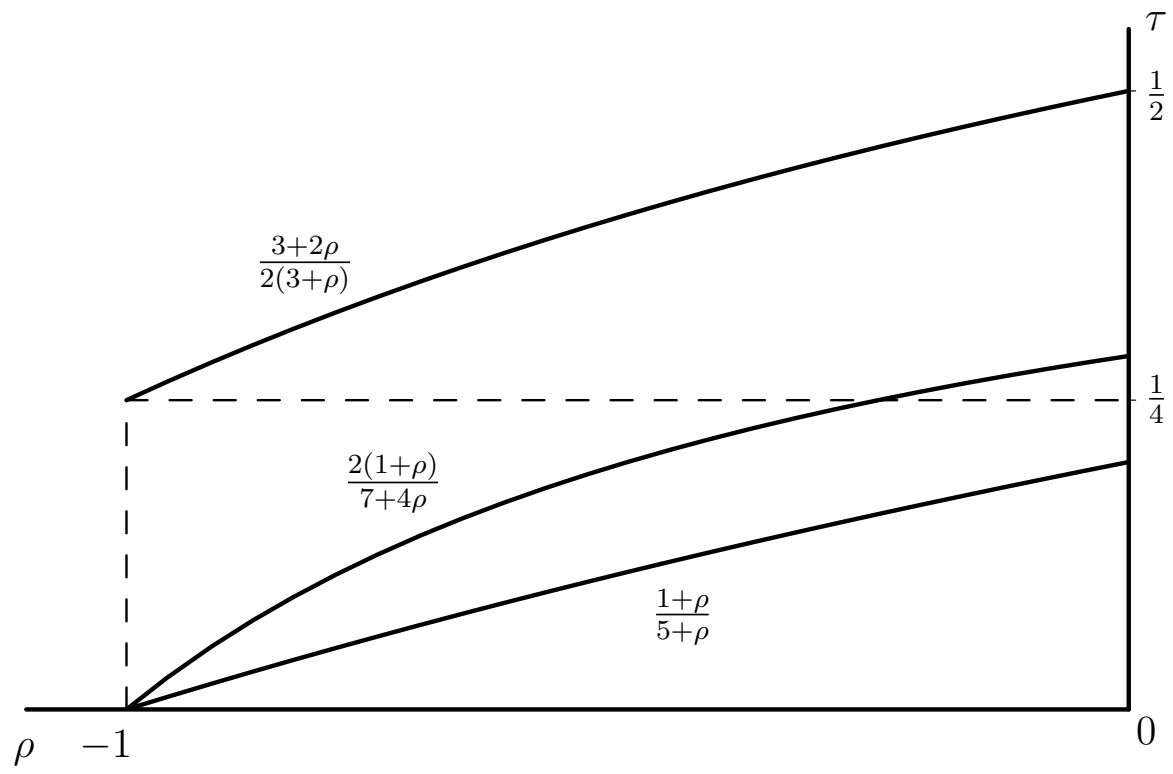

Figure 1: Conditions (15), (17), and (18) 


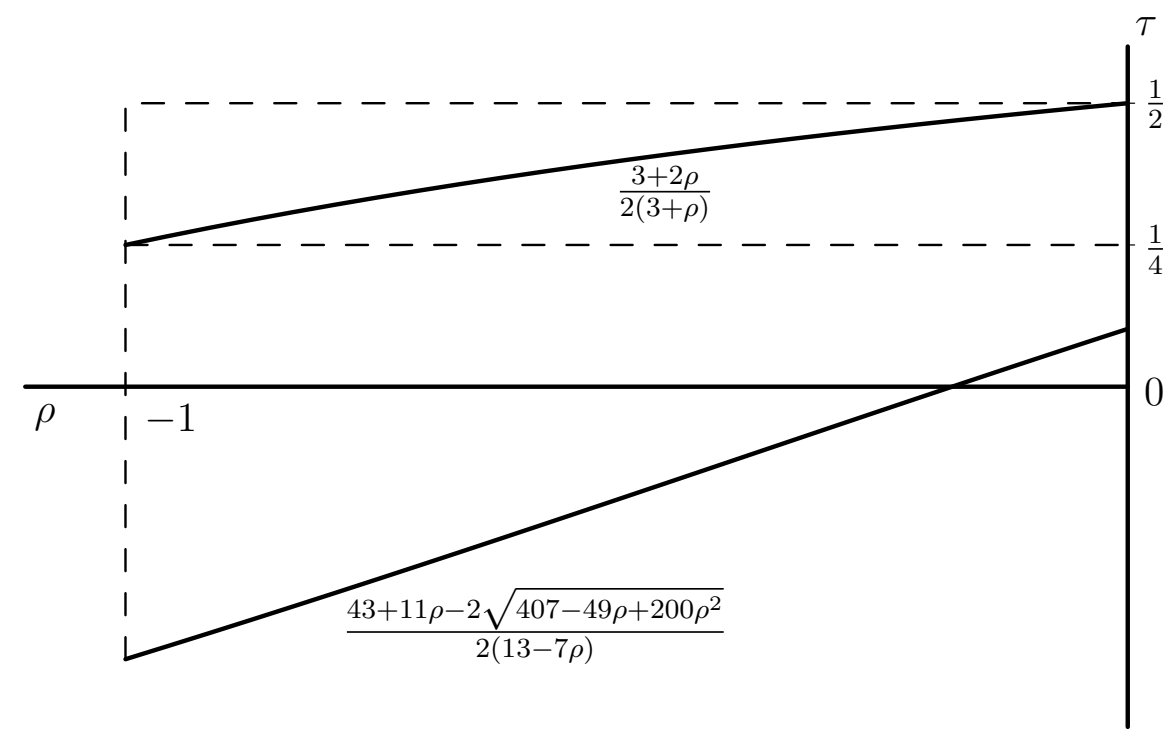

Figure 2: Graphs for the Proof of Lemma 3 


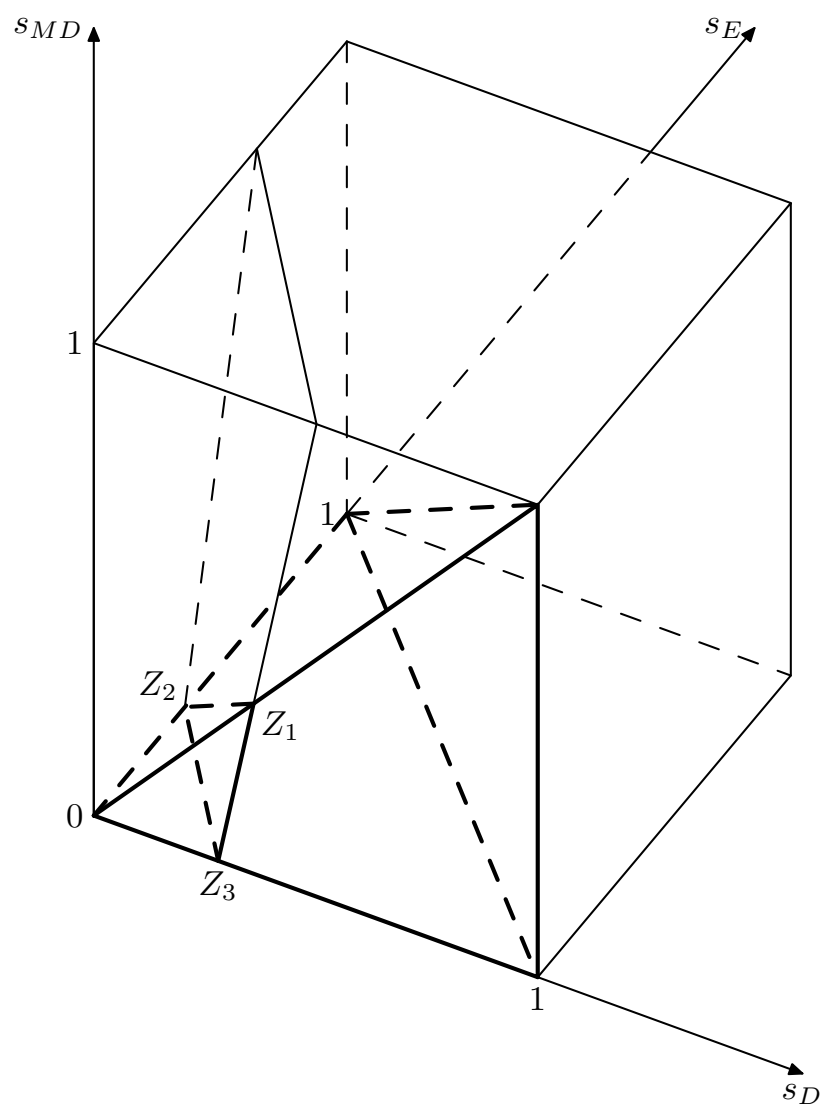

Figure 3: Admissible values of parameters when $s_{M D}+s_{M E}=1$ 